\section{Revista Católica}

\title{
PROPOSTA DE PLANO DE EDUCAÇÃO TECNOLÓGICA PARA AS ESCOLAS DE ENSINO FUNDAMENTAL DE BOA VIAGEM, CEARÁ
}

\author{
Mariana Pereira Silva \\ Júlio César Cavalcante Bezerra \\ Maria Dias Cavalcante Vieira \\ Leonardo Rocha Moreira \\ Maria de Lourdes da Silva Neta
}

\begin{abstract}
RESUMO
O artigo em questão foi elaborado abordando o uso da tecnologia na sala de aula, baseando-se nas habilidades definidas no documento de referências de formação em computação para educação básica da Sociedade Brasileira de Computação SBC. Este trabalho teve como objetivo a criação de um plano de educação tecnológica para educação básica, capaz de auxiliar os alunos no desenvolvimento de habilidades computacionais, adquiridas no desenvolvimento de atividades de informática, matemática e inglês usando ferramentas digitais. A pesquisa aconteceu em uma escola de ensino fundamental no município de Boa Viagem. Durante a pesquisa foi ofertado curso de informática em horário extracurricular quando abordou-se desde conceitos de computação, incluindo manutenção de computadores, segurança da informação e programação. Em paralelo trabalhou-se com os professores o uso de ferramentas como Khan Academy e Duolingo. Conclui-se que ao utilizar o computador nas aulas de matemática e inglês, os alunos demonstraram forte interesse em realizar as atividades, mantendo o foco e melhor assimilação dos conteúdos. Com a pesquisa bibliográfica e a experiência na escola, foi possível perceber as vantagens em incluir no currículo escolar, disciplinas ou componentes que contribuam com o desenvolvimento de competências digitais, mas ainda há um grande caminho a ser percorrido no que se refere a infraestrutura e formação de professores.
\end{abstract}

PALAVRAS-CHAVE: Educação Tecnológica. Ensino personalizado. TDIC's.

\section{EDUCATIONAL TECHNOLOGY PLAN FOR ELEMENTARY SCHOOLS IN THE CITY OF BOA VIAGEM, CEARÁ}

\begin{abstract}
This paper approached the use of technology in the classroom, based on the skills defined by Brazilian Computer Science - SBC reference document concerning computer training for basic education. This study aimed at creating a technological education plan for basic education, which it could be able to support the students to develop computer competencies acquired during computer, mathematics and English activities using digital tools. The research took place at an elementary school in the city of Boa Viagem. During the research, a computer course was offered as an extracurricular activity with computer concepts, including computer maintenance, information security and programming. At the same time, teachers were able to work with tools such as Khan Academy and Duolingo. To sum up, when using the computer in math and English classes, the students showed a steady interest in accomplishing the activities, keeping focused on the content learning. Along with the bibliographical research and the school experience, it was feasible to observe advantages to include in the school curriculum, disciplines or components which contribute to the development of digital competencies; however, there is a long path to be paved away regarding infrastructure facility and teacher training.
\end{abstract}

KEYWORDS: Technology Education. Personalized Teaching. TDIC's.
Enviado em: 13/01/2018

Aceito em: 26/03/2018 Publicado em: 30/04/2018 


\section{INTRODUÇÃO}

As tecnologias digitais vêm fazendo parte da vida da maioria das pessoas, seja em mídias sociais, jogos, sites de notícias ou outras formas de entretenimento. Esta pesquisa teve como base 0 documento de referências da Sociedade Brasileira de Computação - SBC de formação em computação para educação básica, a fim de propor um plano de utilização das Tecnologias Digitais da Informação e Comunicação - TDIC's para as escolas do município de Boa ViagemCeará.

Atualmente, as pessoas têm acesso frequente a muitas informações, como foi apontado por Lastres et al. (2002) na era do conhecimento, no qual as pessoas acessam de maneira rápida e abundante as informações. É importante está em contato com o uso das tecnologias, porém é imprescindível dispor de informações e preparação que permitam as pessoas obterem conhecimento sobre essas tecnologias e dominá-las.

Um dos principais meios que aproximou a tecnologia das pessoas, foram os dispositivos móveis, que oferecem mecanismos da tecnologia de maneira prática e de acesso fácil em qualquer local que o usuário estiver. Segundo argumento de Getschko (2015), a disseminação do uso de dispositivos móveis sem fio, a Internet, guia novas possibilidades para o uso contínuo das TDIC's. Seu uso social por crianças e jovens provoca mudanças visíveis nos sentidos que atribuem relações à vida, à tecnologia e ao saber, expandindo 0 desenvolvimento do que é habitual chamar de "cultura digital".

Raab et al (2017), entende a importância do ensino da computação na educação básica, acreditando que o ensino da computação permeia todas as outras áreas do conhecimento. O documento de referência, publicado em 2017, apresenta habilidades que podem ser trabalhadas desde a educação básica ao ensino médio.

Como analisa Johnson et al (2015), está surgindo um movimento feito para reinventar aquele paradigma da sala de aula tradicional, reorganizando toda a experiência escolar. Como a tecnologia tem o poder de atrair a atenção, descontrair e entreter as pessoas, acredita-se que utilizando softwares educativos, pode ser conquistada a atenção do aluno, e motivá-lo a desenvolver atividades da escola que ao invés de serem escritas à mão, o aluno utiliza do computador e internet para realizá-las. Essa influência é conduzida grande parte pela intervenção das abordagens inovadoras de aprendizagem.

Dessa forma, este trabalho estudou a motivação dos alunos a estudar através das ferramentas digitais, com foco na absorção do conhecimento, tornar as aulas mais dinâmicas, alterando aquele modelo de ensino tradicional em que o aluno só escuta o que o professor diz, e a escola não procura desenvolver habilidades como a curiosidade, investigação e resolução de problemas.

Assim, o objetivo geral desta pesquisa foi propor um plano de utilização de TDIC's aplicado às turmas de nono ano do ensino fundamental do município de Boa Viagem no estado do Ceará e tem como objetivos específicos: Analisar o uso de laboratórios de informática nas escolas do município de Boa Viagem; Investigar tecnologias, metodologias e softwares educativos que estimulem o aprendizado, criatividade e inovação; Validar a proposta de utilização de tecnologias digitais para as turmas de nono ano; Analisar a metodologia e conteúdo do projeto e-jovem, como proposta para utilização no ensino fundamental.

\section{REFERENCIAL TEÓRICO}

O Governo do estado do Ceará, através da Secretaria de educação - SEDUC, desenvolve diversas ações com a intenção de otimizar a qualidade da educação, ações estas, que alimentam a aprendizagem do aluno, a valorização do profissional da educação e infraestrutura física e pedagógica na escola. Avançaramse as ações para melhorar os resultados da aprendizagem dos alunos da rede pública até o $5^{\circ}$ ano. Foram desenvolvidos projetos para a educação, entre eles: Programa Alfabetização na Idade Certa, + PAIC que visa à alfabetização na idade correta, Escolas Profissionais - EEEP's, que aplicam cursos técnicos integrados ao ensino médio, Projeto e-jovem que oferece formação tecnológica e empreendedora para alunos concluintes do ensino médio, entre outros.

Entre esses projetos, destaca-se o Projeto ejovem, pois oferece formação em TDIC's com ênfase no protagonismo juvenil. O projeto é dividido em etapas na qual o módulo fundamental é voltado para alunos do ensino fundamental, o módulo 1 para estudantes do ensino médio e módulo 2 para educandos do ensino médio ou egressos da rede pública de educação.

Segundo a Secretaria de Educação de Boa Viagem (2016), através do Sistema Permanente de Avaliação da Educação Básica do Ceará- SPAECE realizado no ano de 2016, o município de Boa Viagem apresentou situação crítica no $9^{\circ}$ ano, na disciplina de matemática. A cidade ficou na posição 170 em relação às 184 cidades que realizaram a prova. Na disciplina de língua Portuguesa, a situação do estado foi ainda mais crítica, a cidade ficou na posição 177.

Diante dessas informações, pensou-se como a escola pode fazer uso das TDIC's no processo de aprendizagem e desenvolvimento escolar. Conforme Gil (2006), a educação não se diferencia dos outros sistemas sociais quanto à influência das TDIC's, e muitas crianças estão crescendo em ambientes contornados pela tecnologia. A socialização de crianças e jovens atualmente acontece de maneira muito diferente da dos seus pais e professores. O computador, a TV, o cinema e jogos digitais atraem a atenção de mais jovens de maneira especial, portanto acaba estimulando o uso cada vez mais frequente das ferramentas digitais, uma vez que os jovens estão descobrindo um mundo no qual possuem uma ferramenta poderosa nas mãos onde têm acesso à informação de maneira rápida e consistente.

Desse modo, torna-se necessário que 0 indivíduo desenvolva e utilize estratégias para lidar com 
as novas exigências de criatividade, principalmente, do mercado de trabalho. Freeman (2009) apresenta em sua obra que todo mundo já teve o desejo de aprender algo novo. O problema é que na maioria das vezes quando chega na segunda página, o leitor já está desanimado com tantos textos e mais textos. Acontece que o cérebro presta atenção em coisas que saiam do comum, que sejam estranhas, inesperadas, impressionantes.

$\mathrm{Na}$ maneira apresentada por Johnson et al (2015), as principais tendências de tecnologias na educação, que terão grande impacto a longo prazo na educação, são: Pensar como as escolas funcionam: fazendo a análise das metodologias de ensino atuais; Mudança para abordagens de aprendizagem profunda: na qual o ensino se volta a investigação e resolução de problemas; Aumento das abordagens de aprendizagem colaborativa: que remete os aluno e professores a desenvolverem atividades juntos, Alunos de consumidores a criadores: nas escolas ao redor do mundo, os alunos estão explorando conteúdos através do ato de criação ao invés de consumir conteúdos, Aumento do uso da aprendizagem híbrida: na qual os alunos têm parte dos conteúdos online; e aumento da aprendizagem STEAM: onde os alunos têm a aprendizagem voltada para ciências, tecnologia, engenharia e matemática. Todas essas áreas são prováveis de causar forte impacto e grande influência no planejamento tecnológico e na tomada de decisão.

Nas declarações de Raab et al (2017), a computação está dividida em três eixos, são eles: pensamento computacional, mundo digital e cultura digital, no qual através deles é possível desenvolver habilidades focadas na resolução de problemas, conhecimento de componentes físicos e virtuais, fortalecendo a dinâmica da comunicação e informação, dando poder de opinião que antes era somente dos livros e autores. Os três eixos aliados aos conteúdos em sala de aulas, são capazes de abrir novos horizontes da educação, levando os estudantes a trabalharem em sala de aula com uma melhor comunicação entre os professores e colegas, investigando e descobrindo os próprios resultados através da solução de problemas.

Com a utilização do plano de educação tecnológica, espera-se que os baixos índices de rendimento do ensino fundamental, como mostram os dados do SPAECE, sejam elevados e que através do uso da tecnologia, os estudantes possam tornar-se buscadores do próprio conhecimento, aprendendo os conteúdos de maneira dinâmica e sem forçar 0 aprendizado. Ao estudarem em ferramenta digital, os alunos mantêm foco e objetivo no conteúdo, o que pode tornar a absorção do conteúdo mais eficiente.

Durante o desenvolvimento da pesquisa, foram utilizadas três plataformas online de aprendizagem personalizada, as mesmas estão descritas abaixo:

Segundo a Fundação Lemman (2017), a plataforma Khan Academy, é o maior site para aprender matemática do mundo. Criado em 2006 pelo educador americano Salman Khan, ela oferece vídeo aulas e mais de 300 mil exercícios completamente gratuitos que podem ser acessados a qualquer hora do dia em qualquer local. $O$ site oferece ensino personalizado: reconhece quais habilidades o aluno domina e quais ainda precisa praticar. Além disso, o professor tem acesso imediato ao desempenho de seus alunos, podendo identificar as dificuldades de cada um. Basta ter um computador com acesso à Internet.

Figura 1 - Atividade sobre o teorema de Pitágoras no site Khan Academy

Use o teorema de Pitágoras para calcular o comprimento dos lados de triângulos retângulos

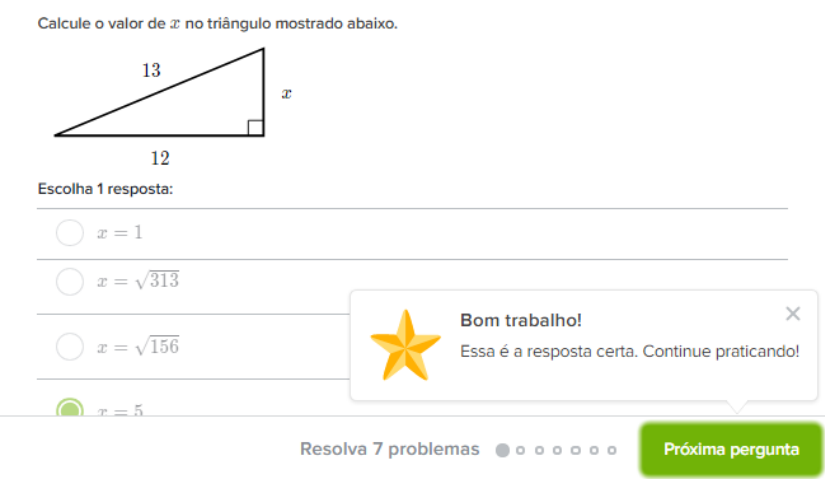

Fonte: www.khanacademy.org

Ainda para a Fundação Lemman (2017), a plataforma Code.org que foi utilizada na aplicação do projeto, é uma organização sem fins lucrativos cujo objetivo é divulgar e ensinar programação a pessoas de todas as idades. A instituição tem parcerias com vários gigantes da tecnologia, e algumas das aulas são ministradas por personalidades da área, como Mark Zuckerberg e Bill Gates, por exemplo. Traduzido como "A Hora do Código do Brasil", o projeto liderado pela Fundação Lemann, visa a desmistificar a programação e apresentar material de qualidade para que pais, professores e alunos tenham acesso às matérias da área de forma amigável.

Figura 2 - Exemplo da atividade Programação com Ana e Elsa no site Learn Code.

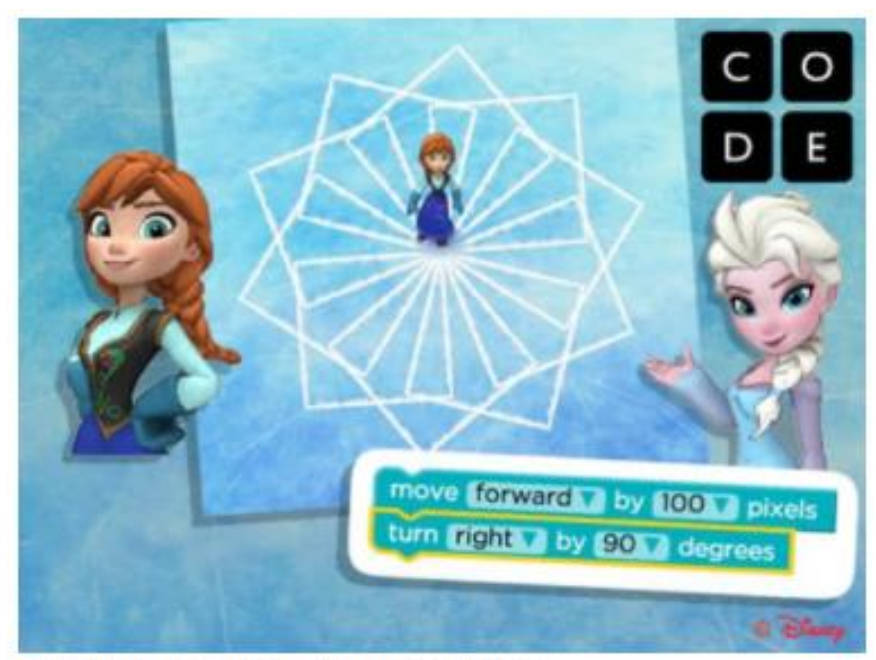

Programe com a Anna e a Elsa

A partir do $2^{\circ}$ ano $\mid$ Blocos

Fonte: https://code.org/learn

Duolingo (2017) o Duolingo é o maior site de ensino de línguas do mundo, é totalmente gratuito e possui vários idiomas, o aprendizado é bem intuitivo, e o aluno ganha pontos ao acertar aposta corrida com 0 
relógio e avança de nível após concluído. As aulas são divididas em pedaços e são eficazes.

Figura 3 - Exemplo de atividade de tradução no site Duolingo.

\section{Traduza este texto}

(41) I am a girl.

Escreva Em Português

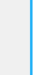

Fonte: www.duolingo.com

As imagens acima apresentaram atividades em execução no site Duolingo.

\section{METODOLOGIA}

A presente pesquisa caracterizou-se como uma investigação exploratória de caráter qualitativo. O trabalho foi desenvolvido por meio de pesquisas sobre as TDIC's na educação. A pesquisa foi realizada em artigos, livros, revistas relacionadas ao assunto, no qual foram comparadas as ideias de outros autores com as do trabalho em questão, também foi analisado e usado como base o documento de Referências do Ensino da Computação na Educação Básica (2017), no qual foram observadas habilidades a serem desenvolvidas pelos alunos através do estudo da computação.

A pesquisadora também buscou através da Internet sites e softwares que ensinam lógica de programação, utilizando programação em blocos que usam recursos de animação e passos sequenciais que despertam 0 interesse dos alunos. Além disso, foi estudado 0 site Duolingo que ensina línguas gratuitamente, foi analisado se o site supria de maneira complementar as atividades dos alunos e o site Khan Academy que ensina matemática através de vídeos e atividades práticas com conteúdo divididos por grau de escolaridade que permite a adequação de conteúdo a turma específica, em relação a investigação exploratória. O autor seguiu os seguintes passos:

\section{$1^{\circ}$ Passo: Reunião pré-plano}

Foi realizada uma reunião de apresentação da proposta com a Secretaria de Educação do município de Boa Viagem Ceará na qual foi apresentado o computador e a Internet como ferramentas facilitadoras no ensino para tornar o mesmo mais dinâmico e atraente. Na reunião, foi apresentado exemplos de sucesso, utilizando diferentes metodologias de ensino.

\section{$2^{\circ}$ Passo: Plano de educação}

Baseado na forte influência da tecnologia na vida dos adolescentes, e refletindo em uma maneira de deixar o aluno mais empenhado a aprender e frequentar a escola, foi elaborado um plano de educação, utilizando tecnologia para os alunos do $9^{\circ}$ ano do ensino fundamental da cidade de Boa Viagem do estado do Ceará. O plano teve como base as referências do ensino da computação na educação básica, e a Lei 1.329 criada pela prefeitura do município Boa Viagem Ceará que institui o programa de empreendedorismo social e capacitação tecnológica.

Tal plano teve o uso do computador como um dos meios que o aluno utilizou para estudar na escola as disciplinas de inglês e matemática. Foi realizado em forma de curso extracurricular aulas de informática básica nas quais os alunos tiverem formação de conceitos importantes de informática, como: funcionamento da internet, segurança de informação, hardware e software, conceitos importantes como Netiqueta e Cyberbuling até a parte de lógica de programação, aprender conceitos de algoritmos e processamento de informação como também conceitos de lógica para serem utilizados em determinada linguagem de programação.

\section{$3^{\circ}$ Passo: Aplicação/ Teste}

As formações de informática aconteceram 3 vezes por semana, em horário de contra turno, 3 horas por dia. Já o conteúdo de inglês foi realizado uma formação com a professora da disciplina, e aconteceram dois encontros nos quais foram realizadas atividades na plataforma, onde foi percebido forte interesse e participação da turma através de diálogos e empenho em realizar as atividades propostas, porém os alunos não tiveram acesso individual às máquinas com os devidos sites citados anteriormente.

\section{khan Academy}

$4^{\circ}$ Passo: Formação dos professores em

Após a realização do teste com os alunos, foi realizada uma formação do Khan Academy com 40 professores de matemática da Coordenadoria Regional de Desenvolvimento da Educação - CREDE 12. O treinamento aconteceu no laboratório de informática do Centro Universitário Católica de Quixadá - Unicatólica, no qual os professores conheceram a ferramenta, testaram como criar turmas, como recomendar tarefas às turmas e demonstraram interesse em utilizá-la em suas salas de aula. Os professores também tiveram acesso à plataforma Learn Code, onde puderam realizar atividades de lógica de programação, envolvendo fundamentos matemáticos e animações gráficas. Após a formação, os docentes responderam um questionário para avaliação da plataforma e possibilidade de uso em sala.

\section{RESULTADOS E DISCUSSÕES}

Esse projeto atende a uma demanda do município de Boa Viagem, visto que no dia 06 de julho de 2017, foi publicada a Lei 1.329 que constitui o programa de empreendedorismo e capacitação tecnológica, cujos objetivos são fomentar 0 empreendedorismo social e formação tecnológica na comunidade discente da rede pública de ensino. $O$ projeto também visa a possibilitar aos alunos e professores a utilização de ferramentas tecnológicas que potencializam o processo ensino-aprendizagem.

A Lei serve de base para implantação do projeto, desde que vise a revitalização e manutenção contínua dos laboratórios de informática, e fortalecimento do ensino de tecnologia na cidade.

Foi realizada a análise da utilização dos laboratórios escolares. Dados da Secretaria de Educação do município de Boa Viagem Ceará, apresentam que 64 escolas de ensino fundamental em 
todo o município possuem laboratório de informática, no qual desse total, apenas 39 possuem acesso à internet.

Os resultados da pesquisa foram obtidos através de formulários preenchidos pelos alunos, professores e diretora da escola. Devido ao baixo desempenho das máquinas do laboratório, não foi possível registrar o progresso individual dos alunos. Após a aplicação, os alunos tiveram acesso a um formulário no qual expuseram suas opiniões sobre a aula que os mesmos participaram, utilizando os recursos digitais.

Na parte do Curso de Lógica de Programação, houve um alto índice de desistência, os alunos alegavam que por ser em horário extracurricular, os mesmos tinham dificuldades em acordar cedo e de deslocamento, portanto o curso concluiu apenas com duas alunas.

A atividade realizada pelas alunas foi, programação com Anna e Elsa, na qual era um conjunto de 20 fases, onde em cada fase o nível de dificuldade aumentava. Nessas atividades, as alunas tiveram acesso à ideia de algoritmos, sequências de passos, comandos de direção e laços de repetição. O resultado das atividades realizadas pelas alunas pode ser visto na imagem abaixo:

Figura 4 - Resultado final da atividade Programação com Ana e Elsa

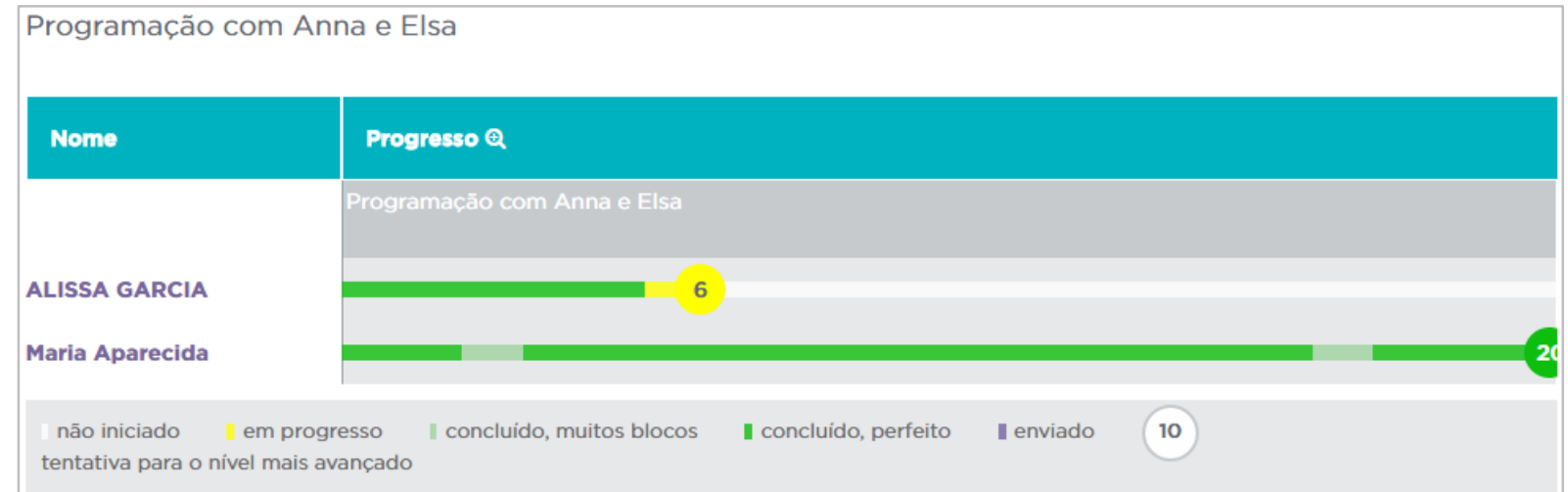

Fonte: https://code.org/learn

$\mathrm{Na}$ aula de matemática, o professor utilizou o site Khan Academy. Depois da realização da aula, os alunos responderam a um questionário sobre a aula, os resultados foram obtidos, de maneira online e todos responderam com suas próprias opiniões sem identificação. A primeira pergunta foi: $\mathrm{Em}$ qual dos pontos abaixo você classifica o Aplicativo? As alternativas: eram chato e cansativo; Divertido e de fácil compreensão do conteúdo; Não gostei; e a explicação não é clara. O resultado foi $6,5 \%$ chato e cansativo, 90,3 $\%$ Divertido e de fácil compreensão do conteúdo, e 3,2 \% Não gostei, a explicação não é clara.

A última pergunta foi descritiva realizada através do formulário, a pergunta foi: Diga o que você achou do uso do Aplicativo Khan Academy nas aulas. As respostas mais repetidas foram: legal e muito bom com $6,5 \%$.

Nas aulas de Língua Inglesa, foi utilizado o site Duolingo. O site treina de maneira gameficada, a escrita, a audição e fala dos alunos. Após o uso do site na aula de língua inglesa, os alunos preencheram um formulário, os resultados foram obtidos, de maneira online e todos responderam com suas próprias opiniões sem identificação. A primeira pergunta foi: $\mathrm{Em}$ qual dos pontos abaixo você classifica o Aplicativo?

As alternativas eram: chato e cansativo; divertido e de fácil compreensão do conteúdo; não gostei; e a explicação não é clara. O resultado foi $3,4 \%$ chato e cansativo, 96,6 \% Divertido e de fácil compreensão do conteúdo, e 0 \% Não gostei, a explicação não é clara. A pergunta descritiva realizada através do formulário foi: Diga o que você achou do uso do Aplicativo Duolingo nas aulas, a resposta mais frequente foi, bom com $10,3 \%$.

Através da experiência com a realização do trabalho, foi observado que os alunos não possuem habilidades digitais básicas descritas nas referências do ensino da computação da educação básica (2017), e que ao utilizarem um plano de educação tecnológica, os mesmos podem desenvolver habilidades como: foco, atenção e capacidade de melhor assimilação dos conteúdos estudados.

Os alunos não tiveram acesso diretos as máquinas devido problemas de infraestrutura, e rede local, porém a prefeitura do município está investindo na contratação de monitores para os laboratórios de informática e fazendo uma revitalização dos ambientes, através da secretaria de tecnologia, nas escolas municipais, e com a utilização de um plano de educação tecnológica, espera-se que os alunos desenvolvam as habilidades descritas nas referências do ensino da computação na educação básica e melhorem seus níveis de rendimento escolar.

Ao final da aplicação com os alunos, foi repassado aos professores das disciplinas de Língua inglesa, Matemática e a diretora da escola, um questionário solicitando a opinião dos mesmos sobre o projeto. As falas do corpo escolar envolvido foram às seguintes:

Professora de Língua Inglesa: Poderia ajudar mais os alunos de língua inglesa.

Professor de Matemática: Como ferramenta para as aulas de reforço e para tornar as aulas mais atrativas.

Diretora da escola: $O$ projeto é bem interessante, os alunos gostaram bastante das aulas. São atrativas e de fácil entendimento, porém não contamos com profissionais para dar continuidade a esse belíssimo trabalho. A Mariana Pereira desenvolveu com muita 
presteza a seu projeto, interagiu com professores e alunos. O LEI deixa um pouco a desejar, por falta de material e manutenção das máquinas.

Após a conclusão com os alunos na escola, foi realizada uma formação com 40 professores de matemática da CREDE 12. O resultado pode ser visto a seguir através das seguintes perguntas, seguidas das respostas: Pelo que você conheceu da ferramenta Khan Academy, acredita que a mesma pode ajudá-lo na aprendizagem de matemática na escola? As alternativas eram sim, não e talvez. O resultado foi $89,5 \%$ sim, $0 \%$ não e 10,5 \% talvez.

Com devida formação da ferramenta, você se considera capaz de ministrar suas aulas, usando a ferramenta de maneira complementar? As alternativas eram sim, não e talvez. O resultado foi $94,7 \%$ sim, 5,3 \% não.

Marque sua opinião em relação ao ensino de matemática atual nas escolas. As alternativas eram: está ótimo, não precisa mudar, $\mathrm{O}$ uso de uma plataforma de ensino personalizado aumentaria o interesse dos alunos e os alunos não gostariam de utilizar esta ferramenta. O resultado foi 5,3 \% Está ótimo, não precisa mudar, 94,7 \% O uso de uma plataforma de ensino personalizado aumentaria o interesse dos alunos e $0 \%$ Os alunos não gostariam de utilizar esta ferramenta.

A tabela abaixo apresenta as respostas dos professores a pergunta descritiva do formulário, na qual eles opinaram sobre o uso da ferramenta. As respostas podem ser vistas abaixo:

Figura 5 - Respostas dos professores que participaram da formação sobre Khan Academy.

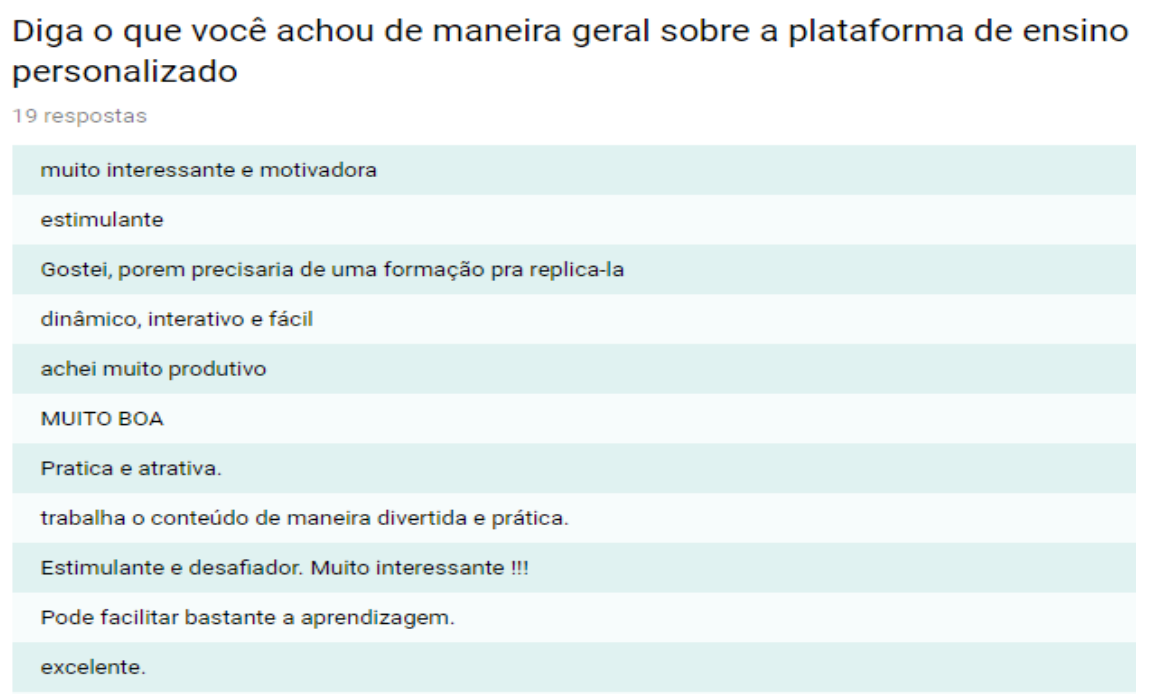

\section{Fonte: Formulários do Google}

Com base nos resultados, elaborou-se um plano de educação tecnológica. Este plano foi elaborado baseado no documento de referências do ensino da computação na educação básica, publicado em julho de 2017 pela Sociedade Brasileira de Computação - SBC, no qual visa a desenvolver habilidades digitais nos alunos de ensino fundamental, assegurando-lhes competências para o manuseio e domínio das tecnologias para uso pessoal e escolar.

As atividades descritas abaixo estão associadas às habilidades definidas no documento de referência identificadas pelos eixos do ensino da computação: Pensamento Computacional (PC), Mundo Digital (MD) e Cultura Digital (CD). 
Quadro 1 - Plano de Educação Tecnológica

\begin{tabular}{|c|c|c|}
\hline Informática básica & Hora do código Programaê & Conteúdo paralelo \\
\hline $\begin{array}{l}\text { - } \text { Cuidados com o computador/ } \\
\text { Manutenção preventiva e } \\
\text { corretiva } \\
\text { - Ferramentas de escritório } \\
\text { - Internet/Mídias sociais e } \\
\text { Netiqueta } \\
\text { - Segurança da informação }\end{array}$ & $\begin{array}{l}\text { - Hora do código (Programação com } \\
\text { Ana e Elsa, Angry Birds, Mine Craft) } \\
\text { - Trilhas de programação } \\
\text { - Scratch } \\
\text { - Robótica Educacional }\end{array}$ & $\begin{array}{l}\text { - Khan Academy nas aulas de } \\
\text { matemática } \\
\text { - Duolingo nas aulas de inglês }\end{array}$ \\
\hline $\begin{array}{l}\text { [CD] Utilizar ferramentas } \\
\text { computacionais para agregar, } \\
\text { manipular e gerar } \\
\text { informações a partir dos dados. } \\
\text { [CD] Estabelecer critérios para } \\
\text { sistematizar a busca e seleção } \\
\text { de dados e } \\
\text { informações, de modo efetivo, } \\
\text { ético e seguro. } \\
\text { [MD] Estabelecer relação entre } \\
\text { hardware e software } \\
\text { (camadas/sistema } \\
\text { operacional) em um nível } \\
\text { elementar. } \\
\text { [MD] Reconhecer a estrutura e } \\
\text { o funcionamento } \\
\text { da Internet. } \\
\text { [CD] Utilizar ferramentas } \\
\text { computacionais para agregar, } \\
\text { manipular e gerar informações } \\
\text { a nartir dos dados }\end{array}$ & $\begin{array}{l}\text { [PC] Utilizar linguagens visuais e língua } \\
\text { nativa para representar dados e } \\
\text { processos. } \\
\text { [PC] Construir soluções de problemas } \\
\text { usando a técnica de generalização, } \\
\text { permitindo o reuso de soluções de } \\
\text { problemas em outros contextos, } \\
\text { aperfeiçoando e articulando saberes } \\
\text { escolares. } \\
\text { Reparação do LEI } \\
\text { Deve ser realizada uma análise de todo } \\
\text { o laboratório de informática, testes de } \\
\text { desempenho e internet individual nas } \\
\text { máquinas. }\end{array}$ & $\begin{array}{l}\text { [PC] Empregar o conceito de } \\
\text { recursão, para a compreensão mais } \\
\text { profunda da técnica de solução } \\
\text { através de decomposição de } \\
\text { problemas. } \\
\text { [CD] Identificar o uso de tecnologia } \\
\text { nas diferentes dimensões da vida } \\
\text { escolar, social, e profissional, } \\
\text { analisando criticamente os riscos e } \\
\text { impactos de seu uso, através de } \\
\text { linhas do tempo, conforme os } \\
\text { índices de qualidade de vida e de } \\
\text { meio ambiente. } \\
\text { Formação de Professores } \\
\text { Deve acontecer formação para os } \\
\text { professores das disciplinas que irão } \\
\text { aderir ao projeto, na formação as } \\
\text { ferramentas deverão ser } \\
\text { apresentadas, e os professores } \\
\text { deverão receber orientações de } \\
\text { criação e controle de turmas através } \\
\text { das plataformas. }\end{array}$ \\
\hline
\end{tabular}

Fonte: Autor.

\section{CONSIDERAÇÕES FINAIS}

Durante a pesquisa foi realizada investigação de softwares educativos, analisando possibilidade de uso em salas de aula, análise do uso do laboratório da escola $X X$, e validação da proposta de projeto através de formulários respondidos por professores e alunos que tiveram participação no projeto, e formação da ferramenta Khan Academy que foi utilizada no projeto para 40 professores da CREDE 12.

Foi abordado conceitos de computação, incluindo manutenção de computadores, segurança da informação e programação. Com a pesquisa bibliográfica e a experiência na escola, foi possível perceber as vantagens em incluir no currículo escolar, disciplinas ou componentes que contribuam com o desenvolvimento de competências digitais, mas ainda há muito o que realizar no que se refere a infraestrutura e formação de professores.

Foi notado também que a estrutura física de boa parte das escolas deixa a desejar. Portanto, com a adesão de um projeto que tocasse nos pontos de conteúdo, estrutura física, formação de professores e revitalização do ambiente na escola, tornaria o aprendizado mais fácil e interativo, consequentemente, elevando o rendimento escolar.

O plano de educação tecnológica foi elaborado com base nas habilidades descritas no documento de referências do ensino da computação para a educação básica, que vai desde estabelecer relação entre hardware e software e identificar o uso de tecnologia nas diferentes dimensões da vida escolar, social, e profissional, analisando criticamente os riscos e impactos de seu uso, através de linhas do tempo, conforme os índices de qualidade de vida e do meio ambiente.

É importante destacar que o município já demonstra interesse no uso de abordagens tecnológicas para a educação. Portanto, espera-se que com a implantação do plano de educação tecnológica que toca nos pontos de formação de professores, revitalização dos laboratórios e formação de conteúdo, os alunos possam desenvolver as diversas habilidades tecnológicas e, consequentemente, melhorar o rendimento escolar. 


\section{REFERÊNCIAS}

BOA Viagem (município). Lei $\mathbf{n}^{\circ} \mathbf{1 . 3 2 9}$, de 06 de julho de 2017. Programa de empreendedorismo social e capacitação tecnológica. Boa Viagem Ceará, 2017.

BRASIL, MINISTÉRIO DA EDUCAÇÃO/INEP. Brasil no PISA 2015: Análises e reflexões sobre o desempenho dos estudantes brasileiros. OCDE/Organização para a Cooperação e Desenvolvimento Econômico. São Paulo: Fundação Santilana, 2016.

DUOLINGO. Aprenda idiomas de graça: para sempre. Disponível em: <https://pt.duolingo.com/>. Acesso em: 04 abr 2017.

FREEMAN, E. Use a cabeça!: padrões de projeto. 2. ed. rev. Rio de Janeiro: Alta Books, 2009.

FUNDAÇÃO Leman, Khan Academy: O maior site de matemática do mundo 2017. Disponível em:

<http://www.fundacaolemann.org.br/khan-academy/>. Acesso em: 18 out. 2017.

GETSCHKO, D. Tic educação 2015. São Paulo: Cetic, 2016.

GIL, J. M. S.; Hernadéz, F. Tecnologias para transformar a educação. São Paulo: Artmed editora, 2006.

GOVERNO DO ESTADO DO CEARÁ. Estatísticas da educação básica do Ceará. Disponível em:

$<$ http://dados.seduc.ce.gov.br/>. Acesso em: 27 mar. 2017.

IBGE. Brasil em síntese 2014. Disponível em: $<$ http://brasilemsintese.ibge.gov.br>. Acesso em: 27 mar. 2017.

JOHNSON, L et. al. Horizon Report: Edição educação básica 2015. Austin: NMC, 2015.

LASTRES, H. M. M. et al. Desafios e oportunidades da era do conhecimento. São Paulo em Perspectiva. v. 16, n. 3, p.60-66, 2002.

LEARN Code. Hora do código 2017. Disponível em: <https://code.org/learn>. Acesso em: 13 nov. 2017.

RAAB, A. et. al. Referenciais de Formação em Computação. CONGRESSO DA SOCIEDADE BRASILEIRA DE COMPUTAÇÃO 2017, 2017, SBC, Porto Alegre, Comissão da educação, 2017. p. 3 - 8.

SECRETARIA DA EDUCAÇÃO DO CEARÁ. Projetos e programas. Governo do Estado do Ceará, 2008. Disponível em: <www.seduc.ce.gov.br/projetos-eprogramas $>$. Acesso em: 06 out 2017.

\section{SOBRE OS AUTORES}

\section{Mariana Pereira Silva}

Centro Universitário Católica de Quixadá, Brasil

Bacharel em Sistemas de Informação pelo Centro Universitário Católica de Quixadá e Técnica em Informática pela Escola Estadual de Educação Profissional David Vieira da Silva. Possui experiência na área de tecnologia da informação com foco em educação técnica e análise de requisitos no desenvolvimento de software. Participou de grupos de estudo em Banco de Dados e Desenvolvimento de Software, tendo concluído, ainda, cursos de automação e robótica, planejamento estratégico com ITIL e comunicação.

E-mail: marilifemari@gmail.com

\section{Júlio César Cavalcante Bezerra}

Centro Universitário Católica de Quixadá, Brasil

Mestre em Computação Aplicada pela Universidade Estadual do Ceará, com graduação em Telemática pelo Centro Federal de Educação Tecnológica do Ceará. Possui experiência na área de Tecnologia da Informação, com ênfase em Educação Profissional e Educação a Distância. Atualmente coordena os cursos de graduação de Sistemas de Informação e Sistemas para Internet do Centro Universitário Católica de Quixadá. Participa de grupos de estudo em Tecnologia aplicada a Educação e Inovação e Empreendedorismo.

E-mail: juliocavalcante@unicatolicaquixada.edu.br

\section{Maria Dias Cavalcante Vieira}

Graduação em Pedagogia pela Universidade Estadual do Ceará (1978) e mestrado em Gestão e Modernização Pública (Municipal e Estadual) pela Universidade Estadual Vale do Acaraú.

\section{Leonardo Rocha Moreira \\ Centro Universitário Católica de Quixadá, Brasil}

Doutorando em Informática Aplicada pela Universidade de Fortaleza. Mestre em Informática Aplicada pela Universidade de Fortaleza.

E-mail: leonardorocha@unicatolicaquixada.edu.br

Maria de Lourdes da Silva Neta

Instituto de Educação, Ciência e Tecnologia do Ceará, IFCE

Doutora em Educação (PPGE - UECE) realizou pesquisas na área de Formação Docente e Avaliação do Ensino - Aprendizagem no Ensino Superior. Integrante do grupo EDUCAS. 